\title{
A review on the internet of things in civil engineering: enabling technologies, applications and challenges
}

\author{
Manisha Gunturi \\ Department of Civil Engineering, Gokaraja Rangaraju Institute of Engineering \& Technology \\ manishag3897@gmail.com
}

\begin{abstract}
The new technology and concepts of IoT is gaining a lot of interest in the recent years. This technology aims at improving the $\backslash$ quality and productivity in various domains. The Internet of Things (IoT) is about the use of sensors and smart devices and to utilize data collected by these embedded sensors and actuators for automation. The technology has proven its significance in many domains and is successfully being used in the various fields of civil engineering. The application of the IoT is paving its way towards smart and sustainable infrastructure. This paper proposes to contemplate the status of usage of IoT in Civil Engineering, its issues and difficulties.
\end{abstract}

\section{Introduction}

Advancements in sensing and IoT technologies are revolutionizing civil infrastructure. The usage of smart devices and IoT is paving the way towards smart and sustainable infrastructure by enhancing the efficiency of the construction sector throughout the entire value chain-from the production of construction materials to the design, construction, operation, and maintenance phases. IoT has many applications in the field of civil engineering such as buildings, roads, bridges, dams, railways, and sewerage systems etc. IoT aims at improving the occupant comfort, efficient operation of building systems, reduction in energy consumption, reduced operating and maintaining costs, increased security, remote access and improved life cycle of equipment and related utilities. Any existing building can be converted into a smart building by installing a few smart devices and sensors connected to a network and adaptable softwares.

A smart building or an intelligent building is any structure that uses automation through Internet of Things to control the building's operations such as HVAC (Heating ventilation Air conditioning), lighting, security, energy optimization etc. This can be employed by the use of sensors, actuators and microchips that can collect the data which is further processed according to the building's functional requirements. This type of infrastructure helps its occupants improve asset reliability and performance in terms of energy efficiency, space optimization, temperature control and minimizes the environmental impact of buildings [1-4]. Smart office buildings, health care facilities, hospitals, smart transportation facilities, educational facilities, smart parking lots, stadiums etc are some of the examples of smart infrastructure.

The modernized sensor-embedded residence with various integrated systems was thought to be the basis of smart buildings in initial research. The system communication between external and internal was operated remotely and efficiently [5-6].

\section{Architecture of loT}

The architecture of an IoT system can be described as a four-stage process in which data flows from sensors attached to "things" through a network and eventually on to the cloud for processing, analysis and storage. This analysed data is then transmitted back to the associated devices for taking appropriate actions [7].

In the Internet of Things, a "thing" could be a machine, a building or even a person. Processes in the IoT architecture also send data in the other direction in the form of instructions or commands that tell an actuator or other physically connected device to take some action to control a physical process [8]. An actuator could do something as simple as turning on a light or as consequential as shutting down an assembly line if impending failure is detected [9]. 


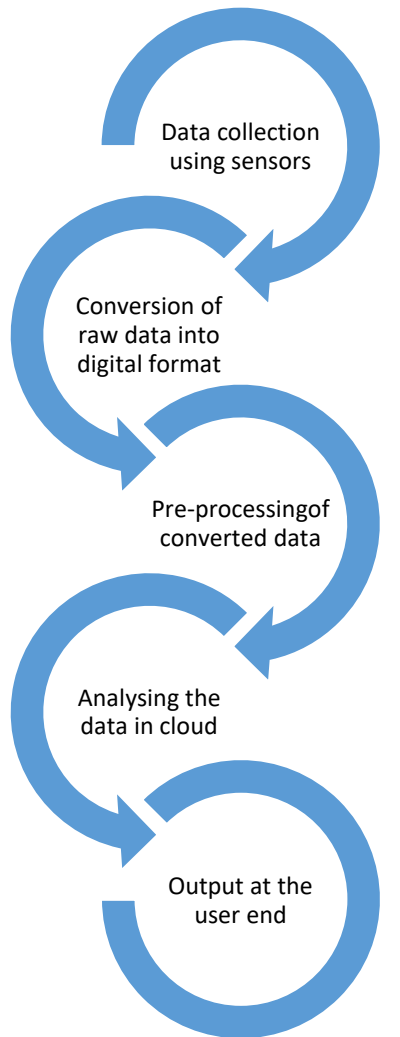

Figure 1: Stages in the IoT technology

\section{Stage 1: Sensors and Actuators - Sensing layer}

The process of collection of data starts with sensors and actuators, the connected devices that monitor or control the physical processes. Sensors are used to monitor the physical state such as temperature, humidity, lighting etc. Various types of sensors are employed for various functions such as thermal sensors for monitoring the temperature changes, motion sensors for detecting any movement etc. These sensors collect the data from the surrounding environment.

The actuators are controlling devices that can perform remediation actions in real time. To avoid the delay of a round-trip of data to the server, analysis of data to determine failure and sending of control to the "thing", this critical processing is performed in close proximity to the process being monitored or controlled.

\section{Stage 2: Internet Gateways and Data Acquisition Systems -Network layer}

The raw data collected by the sensors is then converted into digital format from analog format. The DAS then aggregates and formats the data before sending it through an Internet gateway via wireless WANs (such as Wi-Fi or Cellular) or wired WANs for the next stage of processing. At this stage, the volume of data is huge and needs to be filtered and compressed to an optimum size for transmission to the next stage.

\section{Stage 3: Pre-processing: Analytics at the Edge - Data Processing layer}

The edge device performs some analytics as preprocessing on the data to further reduce its volume for easy transmission to the cloud.

\section{Stage 4: In-depth Analysis in the Cloud or Data Center - Application layer}

At this stage, the collected data is analysed and stored securely in remote locations such as in the corporate data center or in the cloud, where data from multiple field sites and sensors is combined to provide a broader picture of the overall IoT system. Data from the cloud is used by end-user applications like agriculture, health care, aerospace, farming, defense, etc.

\section{Technology:}

The internet of things is all about connectivity i.e. IoT is a system of interconnected digital devices, machines, objects, humans provided with unique identifiers and the ability to transmit and share data over the network without the need of human-tohuman or human-to-computer interaction. Bridging the gap between the physical and virtual worlds, IoT aims at creating smart environments that provide speed and comfort to the occupants [10-12].

The IoT technology can be stacked into four basic technology layers $[13,14]$ :

\section{Applications of IoT in Civil Engineering}

(i) Structural Health Monitoring

Structural health monitoring (SHM) involves monitoring and assessing the condition of a structure under working conditions by tracking parameters like stress, strain, vibrations etc. The emergence of IoT have simplified the manual, laborious task of manual data collection which is inefficient and slow. The collection of real time data of structures can be easily done by installing sensors and actuators in the structures in order to improve the overall performance [15].

(ii) Smart cities

Smart cities use IoT devices such as connected sensors, lights, and meters to collect and analyze data. The cities then use this data to improve infrastructure, public utilities and services, and more.

(iii) Smart homes

A smart home is any home that is equipped with smart devices that are interconnected forming a network. These smart devices enables remote operation of the smart home system. Google Home, Amazon Echo Dot, Apple's Siri etc. form a smart home hub where a number of devices can be connected and remotely operated. 
(iv) Intelligent transportation system

According to the US Department of Transportation, "Intelligent Transportation Systems (ITS) apply a variety of technologies to monitor, evaluate, and manage transportation systems to enhance efficiency and safety." The installation of smart sensors, GPS based tracking systems can improve the overall performance of the transportation systems. With the help of IoT enabled devices, real time data of the exact locations, expected time of arrivals, delays etc can be obtained thereby improving the traffic efficiency and reduces the traffic problems.

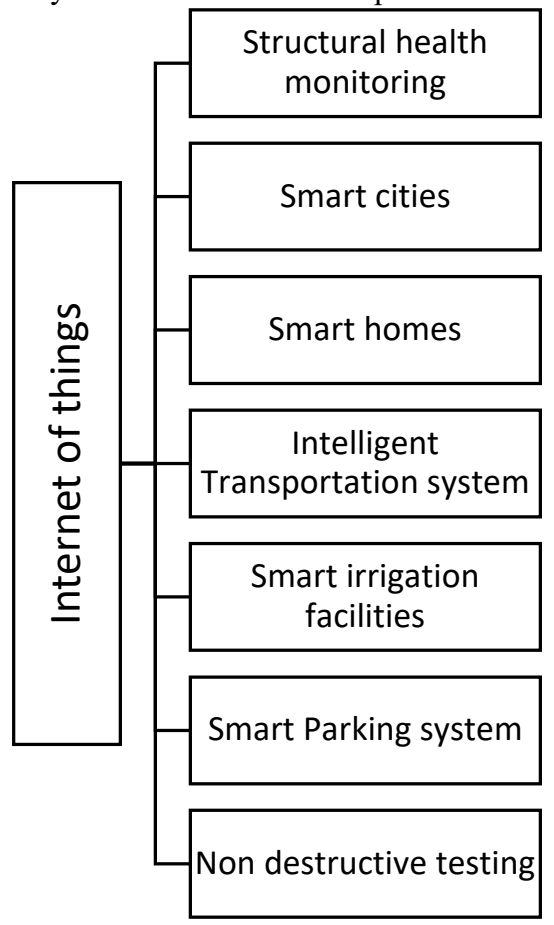

Figure 2: Applications of internet of things in civil engineering

(v) Smart irrigation facilities

Smart irrigation system makes use of IoT based sensors in an extensive way to determine the frequency and depth of irrigation. Sensors of soil moisture content, temperature, piezometers, weather sensors etc are widely used for obtaining data which is then processed and appropriate action (such as turning on/off the water pumps) can be taken without human efforts from a remote web or mobile application.

(vi) Smart parking systems

The parking system can be improved by installing sensors, that can alert the user about occupied or vacant spot via web or mobile applications. This IoT based parking system enables the user for a hassle free parking in less time thereby reducing the traffic volume.

(vii) Non-destructive testing

Non destructive testing is practiced for determining the structural integrity without damaging the structure. The usage of IoT sensors offers the opportunity to extract the required parameters through artificial intelligence, mitigating financial and operational consequences of deterioration and routine manual supervision. In addition to that, maintenance investments and repairs can be predicted efficiently.

(viii) Damage detection of structures

Smart sensors can be installed in the structures or underground mines to predict various parameters like stress, strain, settlements or even seismic activities. This kind of timely detection and continuous monitoring can help prevent or minimize the failures of assets.

(ix) Real-Time Construction Management Solution IoT provides solutions like remote operative equipment in the construction industry to ensure safety of the workforce. In addition to that, the project costs can also be reduced by employing IoT applications like Building Information Modelling which will help to improve the resource efficiency [16].

(x) Project Safety Platform

Use of IoT enabled sensors and wearable in the construction site will improve safety and efficiency of the workforce thereby increasing the productivity. IoT can be used to obtain real time data of the construction sites regarding the harsh working environments, diagnosing and prediction of failures, accidents and mishaps etc. In case of threats or any such incidents, emergency evacuation procedures, preventive measures or rescue activities can be performed immediately [11].

\section{Pros and Cons of IoT:}

The IoT has made our lives a lot simpler and it has much more contributions in almost every domain. This technology has aimed at providing a better quality lives by reducing the physical effort. With the usage of these smart devices, most of the tasks can be done remotely thereby minimizing the human intervention leading to increased productivity. Just like every other technology, Internet of Things has its own Pros and cons. They are:

Pros:

Automation: With the help of automation, the productivity can be increased in addition to production costs thus offering a better profit margin for industries. The higher accuracy in automation will also enhance the uniformity and quality of the products and services.

(i) Efficiency: Utilization of IoT enabled devices, minimizes human intervention and increases machine to machine interactions resulting in much more free time. In addition to that, the machine to machine interaction provides better transparency in the entire process.

(ii) Economy: Although the initial cost for installation of smart devices is higher, it is proven to be economic and cost saving in the long run. 
(iii) Faster Communication: The machine to machine interaction has simplified all the tasks and allows the user to control all the tasks without any difficulty. Smart home devices such as Amazon's Echo dot, Google home and Apple's Siri has simplified even the day to day activities.

(iv) Data accessibility: With the IoT, the data collected can be easily accessed at any particular time which helps further in the decision making process.

\section{Cons:}

(i) Security concerns: The usage of smart devices requires internet connectivity huge data transfer to the cloud. The storage and availability of such huge amount of data on the remote servers has its own drawbacks where unauthorized users and hackers always pose a threat.

(ii) Lag in real time data acquisition: The smart devices need better internet connectivity to perform tasks. Fluctuations in the connectivity and speed of the internet will result in time lag and obtaining real time data becomes difficult in such cases.

(iii) Availability of networks and services: The network connectivity and services which are required for these smart devices cannot be ascertained round the clock due to a number of reasons such as device on the move, weather issues etc.

(iv) Storage and processing of data: The IoT requires a number of interconnected devices to work efficiently which means collection of huge data. It becomes difficult sometimes for transferring, storage and processing of this data. Moreover, it becomes time taking for processing such huge data leading to delays in action.

(v) Accuracy: The time lag and improper network and connectivity issues will result in inaccurate data.

(vi) Compatibility: Since the IoT is still in its emerging phase, most of the existing devices may be compatible with the smart devices. Therefore there exists a need to replace or upgrade the existing devices in order to ensure connectivity with the IoT enabled smart devices. In addition to that the variation in the manufacturing of different devices may give rise to compatibility issues in establishing a proper connection.

(vii)Complexity: Although the technology appears simple to understand, its vast and diverse with multiple functioning layers and large network of devices. Any minute error at a single node can have adverse impact on the output.

\section{Conclusions:}

The advent of IoT provides better insights into the construction industry. The IoT can be applied into various domains of civil engineering. The sensors can be used to monitor various parameters ranging from settlements, stresses, strains, consolidation issues etc. which can assist in avoiding or minimizing accidents and property loss. In addition to that IoT can also be employed efficiently in the construction industry in health and safety issues of the workforce, structural health monitoring. The BIM application can effectively be used in construction management practices. The IoT technology works with minimum hum intervention but it does require human supervision for efficient decision making. The technology is already being employed in various fields of the Civil Engineering and there is a huge scope for improving the efficiency of the IoT enabled smart technologies.

\section{References:}

[1] L. Atzori, A. Iera, \& G. Morabito. The Internet of Things: A survey. Computer Networks, 54(15), 2787-2805, (2010).

[2] D. Bandyopadhyay \& J. Sen. Internet of things: Applications and challenges in technology and standardization. Wireless Personal Communications, 58(1), 49-69, (2011).

[3] Wikipedia contributors. "Internet of things." Wikipedia, The Free Encyclopedia. (2018).

[4] Y. Mehta, "Will Internet of Things Technology Make Life Any Easier?" [online], source: http://iotworm.com/internet-thingstechnology-make-life-easier/, (2015).

[5] D. L. Yang, F. Liu and Y. D Liang, "A Survey of the Internet of Things", International Conference on E-Business Intelligence (ICEBI), (2010).

[6] K. Ding, H. Shi, J. Hui, Y. Liu, B. Zhu, F. Zhang, W. Cao. Smart steel bridge construction enabled by BIM and Internet of Things in industry 4.0: A framework. ICNSC 2018 - 15th IEEE International Conference on Networking, Sensing and Control, 1-5, (2018).

[7] B. Elyse, Internet of Things explained: Your complete guide to understanding IoT, [online], source: http://www.pocketlint.com/news/126559-internet-of-thingsexplained-what-is-it-and-can-it-reallychange-the-world, (2018).

[8] S. Ghimire, F. Luis-Ferreira, T. Nodehi., \& R. Jardim-Goncalves. IoT based situational awareness framework for real-time project management. International Journal of Computer Integrated Manufacturing, 30(1), 74-83, (2017).

[9] K. Harika Devi, P. Sirisha. An Iot Based Solution For Health Monitoring Using A Body-Worn Sensor Enabled Device. Journal 
of Advanced Research in Dynamical and Control Systems 10(9):646-651, (2018).

[10] M. U. Farooq, M. Waseem, S. Mazhar, A. Khairi, T. Kamal. A review of Internet of Things (IoT), International Journal of Computer Applications, Volume 113, Issue 1. (2015)

[11] G. Manisha. An Overview of Internet of Things. Journal of Advanced Research in Dynamical and Control Systems 10(09):659665, (2018).

[12] G. Manisha. Architecture, applications and challenges of internet of things. International Journal of Pure and Applied Mathematics 119(14):231-236, (2018).

[13] K. M. Mehata, S. K. Shankar, N. Karthikeyan, K. Nandhinee, \& H. P. Robin. IoT Based Safety and Health Monitoring for Construction Workers. In 1st International Conference on Innovations in Information and Communication Technology (ICIICT), (2010).

[14] Y. Niu, C. Anumba. W. Lu. Taxonomy and Deployment Framework for Emerging Pervasive Technologies in Construction Projects. Journal of Construction Engineering and Management, 145(5), 1-13, (2019).

[15] W. Rong, and L. Kecheng, "A survey of context aware web service discovery: from user's perspective" Service Oriented System Engineering (SOSE), 2010 Fifth IEEE International Symposium on IEEE, (2010).

[16] J. Robertas, P. Irena, P. Martynas, "Digital dimension of smart cities: critical analysis", 19th International Scientific Conference Proceedings: Economics and Management, Riga, Latvia, PP:146-150, (2014).

[17] T.Srinivas and M. Abinay Raj, Int. J. of Eng.and Adv. Tech. (IJEAT), ISSN: 2249 8958, Volume-8 Issue-6 (2019)

[18] T.srinivas and P. Manoj Anand, Int. J. of Innov. Tech. and Explor. Eng.g (IJITEE), ISSN: 2278-3075, Volume-8 Issue-12 (2019)

[19] T.Srinivas and G. Sukesh Reddy, Int. J. of Eng.and Adv. Tech. (IJEAT), ISSN: $2249-$ 8958, Volume-9 Issue-1 (2019)

[20] T.Srinivas and R. N. Koushik, Int. J. of Innov. Tech. and Explor. Eng.g (IJITEE), ISSN: 2278-3075, Volume-8 Issue-12 (2019), PP $112-117$

[21] K. Sai Gopi, Dr. T. Srinivas and S. P. Raju V, E3S Web of Conferences ICMED 184, 01084GRIET, 28-29 February, https://doi.org/10.1051/e3sconf/2020184011 084(2020)

[22] Jagannadha Kumar, M.V., Jagannadha Rao, K., Dean Kumar, B., Srinivasa Reddy, V., Int.
J. of Civil Eng. and Tech., 9(7), pp. 1133-1141 (2018)

[23] Ganta, J.K., Seshagiri Rao, M.V., Mousavi, S.S., Srinivasa Reddy, V., Bhojaraju, C., Structures 28, pp. 956-972 (2020)

[24] Naidu, K.S.S.T., Rao, M.V.S., Reddy, V.S., Int. J. of Innov. Tech. and Explor. Eng.g (IJITEE), 8(9 Special Issue 2), pp. 641-642 (2019)

[25] Chandana Priya, C., Seshagiri Rao, M.V., Srinivasa Reddy, V., Int. J. of Civil Eng. and Tech., 9(11), pp. 2218-2225 (2018)

[26] Satya Sai Trimurty Naidu, K., Seshagiri Rao, M.V., Srinivasa Reddy, V., Int. J. of Civil Eng. and Tech., 9(11), pp. 2383-2393 (2018)

[27] Supriya, Y., Srinivasa Reddy, V., Seshagiri Rao, M.V., Shrihari, S., Int. J. of Rec. Tech. and Engi., 8(3), pp. 5381-5385 (2019)

[28] Kotkunde, N., Krishna, G., Shenoy, S.K., Gupta, A.K., Singh, S.K. International Journal of Material Forming, 10 (2), pp. 255-266 (2017)

[29] Govardhan, D., Kumar, A.C.S., Murti, K.G.K., Madhusudhan Reddy, G. Materials and Design, 36, pp. 206-214. (2012)

[30] Kumar, P., Singhal, A., Mehta, S., Mittal, A. Journal of Real-Time Image Processing, 11 (1), pp. 93-109. (2016)

[31] Raghunadha Reddy, T., Vishnu Vardhan, B., Vijayapal Reddy, P. International Journal of Applied Engineering Research, 11 (5), pp. 3092-3102 (2016)

[32] Hussaini, S.M., Krishna, G., Gupta, A.K., Singh, S.K. Journal of Manufacturing Processes, 18, pp. 151-158 (2015) 